\title{
Comparison of the Bone Harvesting Capacity of an Intraoral Bone Harvesting Device and Three Different Implant Drills
}

\author{
Hyun-Chang Lim, ${ }^{1}$ Kyung-In Ha, ${ }^{1}$ Ji-Youn Hong, ${ }^{1}$ Ji-Young Han, ${ }^{2}$ Seung-Il Shin, \\ Seung-Yun Shin, ${ }^{1}$ Yeek Herr, ${ }^{1}$ and Jong-Hyuk Chung ${ }^{1}$ \\ ${ }^{1}$ Department of Periodontology, Periodontal-Implant Clinical Research Institute, School of Dentistry, Kyung Hee University, \\ Seoul, Republic of Korea \\ ${ }^{2}$ Department of Dentistry/Periodontology, College of Medicine, Hanyang University, Seoul, Republic of Korea
}

Correspondence should be addressed to Jong-Hyuk Chung; chungjh@khu.ac.kr

Received 17 May 2017; Accepted 23 November 2017; Published 14 December 2017

Academic Editor: Konstantinos Michalakis

Copyright (C) 2017 Hyun-Chang Lim et al. This is an open access article distributed under the Creative Commons Attribution License, which permits unrestricted use, distribution, and reproduction in any medium, provided the original work is properly cited.

\begin{abstract}
The aim of the present study was to compare bone-collecting capacity of bone harvesting device and minimally irrigated lowspeed drilling using three implant systems. One bone harvesting device and three commercially available drill systems were compared using the osteotomies on bovine rib bones. The amount of the collected bone particle and particle size $(<500 \mu \mathrm{m}$ : small, $500-1000 \mu \mathrm{m}$ : medium, and $>1000 \mu \mathrm{m}$ : large) were measured. Total wet $(1.535 \pm 0.232 \mathrm{~mL})$ and dry volume $(1.147 \pm 0.425 \mathrm{~mL})$ of the bone particles from bone harvesting device were significantly greater than three drill systems (wet volume: 1.225 $\pm 0.187-1.27 \pm$ $0.29 \mathrm{~mL}$ and dry volume: $0.688 \pm 0.163-0.74 \pm 0.311 \mathrm{~mL})(P<0.05)$. In all groups, the amount of large sized particles in wet and dry state was the greatest compared to that of medium and small particles. The dry weight of the bone particles showed the same tendency to volumetric measurement. In conclusion, total bone particles and large sized particles $(>1000 \mu \mathrm{m})$ were harvested significantly greater by bone harvesting device than minimally irrigated low-speed drilling. The composition of particle size in all harvesting methods was similar to each other.
\end{abstract}

\section{Introduction}

Autogenous bone is considered the gold standard for implantation because of its biocompatibility and osteogenicity [1, 2]. Peri-implant defects, such as dehiscence or fenestration, have been successfully managed by grafting autogenous bone [3-5]. Autogenous bone for intraoral augmentation can be collected in either block or particulate form and can be used alone or in combination with other bone substitutes from different origins [5-11].

Harvesting autogenous bone is generally presumed to involve a second surgical site and higher patient morbidity. However, autogenous bone can be collected during preparation for implant osteotomy, which is highly advantageous for the patient because it avoids the above-mentioned limitations [12]. The main clinical challenge in collecting bone particles during implant drilling is irrigation. Without proper cooling by irrigation, overheating and subsequent alveolar bone necrosis can occur. An aspiration technique using a specially designed suction device has been proposed, but this may render the collected bone unusable due to contamination by oral bacteria and debris [13]. More recently, a minimally irrigated low-speed drilling technique has been used to collect a significant amount of bone particles [14, 15]. This technique is relatively convenient and easy compared to other autogenous bone harvesting techniques, both device-wise and time-wise.

Commercially available bone substitutes are provided at a uniform range of particle sizes, but the minimally irrigated low-speed drilling technique appears to result in various particle sizes. Bone-forming potential could vary with bone particle size [16]. However, there have been few studies exploring the size of harvested particles from drilling or bone harvesting device. Moreover, the quantity of bone particles 

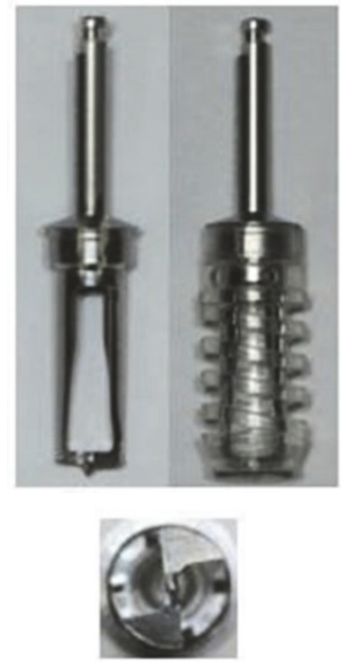

(a)
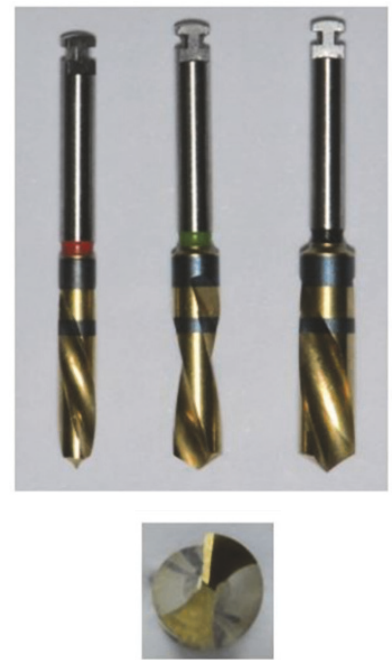

(b)
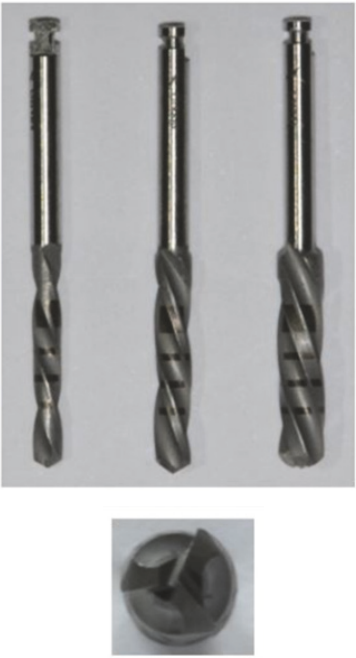

(c)
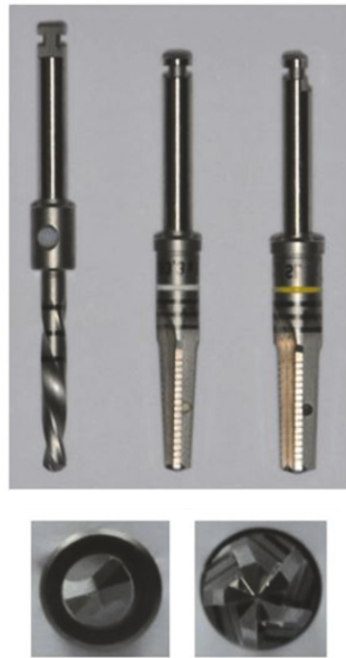

(d)

FIGURE 1: Devices used in the experiment, (a) Group 1. Bone harvesting device, (b) Group 2. Three two-flute sequential twist drills ( $\varnothing$ 2.5, 3.2, $3.7 \times 11 \mathrm{~mm}$ ), (c) Group 3. Three three-flute sequential twist drills $(\varnothing 2.2,2.8,3.5 \times 10 \mathrm{~mm}$ ), (d) Group 4. One two-flute pilot drill $(\varnothing 2.0 \times 11 \mathrm{~mm})$ and two five-flute sequential drills $(\varnothing 3.3,3.8 \times 11 \mathrm{~mm})$.

that can be obtained using various techniques should be investigated because different peri-implant defects require different amounts of bone substitute.

The aim of the present study was to compare the bone harvesting capacity, that is, the size and amount of harvested bone particles, of a specially designed bone harvesting device and minimally irrigated low-speed drilling using three implant systems.

\section{Materials and Methods}

2.1. Experimental Model. The experiment protocol was based on previous studies with modifications $[17,18]$. Briefly, bone harvesting for collection of bone particles was performed on bovine rib bones. Bones with $>10 \mathrm{~mm}$ wide surface were selected. Periosteum was removed to expose the cortical bone. The cortical bone thickness of the bone was measured with a digital caliper (Digimatic caliper, Mitutoyo Co., Kawasaki, Japan).

2.2. Bone Harvesting Device and Drill Systems. One bone harvesting device (Group 1) and drills from three different implant systems (Groups 2, 3, and 4) were used for bone collection. The device for Group 1 includes a cylindrical trephine-like drill (Ø: $4 \mathrm{~mm}$ ) with a hollow part in the center and a stopper which limits the depth of drill penetration up to $4 \mathrm{~mm}$ (Neo AutoChip Maker, Neobiotech, Seoul, Korea). The drills for Groups 2, 3, and 4 have different numbers of flutes. For Group 2, three two-flute parallel-shaped twist drills were sequentially used $(\varnothing 2.5, \varnothing 3.2$, and $\varnothing 3.7 \times 11 \mathrm{~mm}$; Astra Tech Implant System, Mölndal, Sweden). For Group 3, three three-flute parallel-shaped twist drills were sequentially used (Ø 2.2, Ø 2.8, and Ø $3.5 \times 10 \mathrm{~mm}$; Straumann, Basel, Swiss). For Group 4, one two-flute parallel-shaped twist drill ( $\times 11 \mathrm{~mm}$; Camlog, Basel, Swiss) and then two tapered-shaped five-flute straight drills (Ø 3.3 and $\varnothing 3.8 \times 11 \mathrm{~mm}$; Camlog) were sequentially used (Table 1 , Figure 1 ).

2.3. Bone Harvesting and Measurement. Ten osteotomies in one rib bone were performed for each group (10 rib bone for each group) using a Surgic XT plus (NSK, Kanuma, Japan). Drilling speed and torque were set at $100 \mathrm{rpm}$ and $30 \mathrm{Ncm}$, respectively. Osteotomy preparation was designed for installation implants with regular platform (around $\varnothing$ $4.0 \mathrm{~mm}$ ). Drilling was performed using the above-listed drills from smallest diameter to greatest diameter according to the manufacturers' instructions. Saline irrigation during the drilling was minimized according to a previous study [12]. The distance between drilling sites was $8 \mathrm{~mm}$. Bonecollecting and measuring methods were described in our previous study [19]. Briefly, bone particles in the hollow part of the bone harvesting device and the flutes of the drills were collected by scraping into a small bowl. Remnant particles in the osteotomy holes were also collected by thorough saline irrigation. The collected bone particles were packed into a $2 \mathrm{~mL}$ syringe for removing excessive saline and measured total wet volume (JW-1 electronic-scale; Acom, Pochun, Korea). Then bone particles were sieved serially using two sieves (500 $\mu \mathrm{m}$ and $1000 \mu \mathrm{m}$; Chunggye Co., Seoul, Korea). The bone particles were divided into three categories based on particle sizes; $<500 \mu \mathrm{m}$ (small particles; SPs), $500-1000 \mu \mathrm{m}$ (medium particles; MPs), and $>1000 \mu \mathrm{m}$ (large particles; LPs). Then, the wet volume of each category was measured. After drying for 72 hours at room temperature, the total and categorical dry volumes were also measured.

2.4. Statistics. One rib bone was regarded as one unit for statistical analysis, and thus each group was composed of 
TABLE 1: Characteristics of each drill group.

\begin{tabular}{lcccc}
\hline Group & Drill shape & $\begin{array}{c}\text { Flute } \\
\text { number }\end{array}$ & $\begin{array}{c}\text { Diameter } \\
(\mathrm{mm})\end{array}$ & Length $(\mathrm{mm})$ \\
\hline 1 & Straight & 2 & 4.0 & 14 (stopper 4 mm) \\
\hline \multirow{3}{*}{2} & Parallel, twist & 2 & 2.5 & 11 \\
& Parallel, twist & 2 & 3.2 & 11 \\
& Parallel, twist & 2 & 3.7 & 11 \\
\hline \multirow{3}{*}{3} & Parallel, twist & 3 & 2.2 & 10 \\
& Parallel, twist & 3 & 2.8 & 10 \\
& Parallel, twist & 3 & 3.5 & 10 \\
\hline \multirow{3}{*}{4} & Parallel, twist & 2 & 2 & 11 \\
& Tapered, straight & 5 & 3.3 & 11 \\
& Tapered, straight & 5 & 3.8 & 11 \\
\hline
\end{tabular}

10 units, respectively. The average value from each unit was served as a representative for the unit. Statistical analysis was performed using statistical software (SPSS ver. 18.0, SPSS Inc., Chicago, IL, USA). Data were presented as the mean and standard deviation (SD). The Kruskal-Wallis test, followed by the Mann-Whitney test, was used to identify significant differences. Statistical significance was set at $P<0.05$.

\section{Results}

The cortical thickness of the bovine rib bone was $2.297 \pm$ $0.051 \mathrm{~mm}$ on average.

The wet volume of bone particles collected during the 10 osteotomies (1 unit) in each of the four groups is shown in Figure 2. The total wet volume of Group $1(1.535 \pm 0.232 \mathrm{~mL})$ was significantly greater than that of the other groups (Group 2: $1.225 \pm 0.187 \mathrm{~mL}$, Group 3: $1.26 \pm 0.139 \mathrm{~mL}$, and Group 4: $1.27 \pm 0.29 \mathrm{~mL}, P<0.05$ for all comparisons). In intragroup comparisons of wet volume, particle size distribution in all groups showed a similar pattern; the amount of large particles (LPs, $>1000 \mu \mathrm{m}$ ) was greater than medium particles (MPs, $500-1000 \mu \mathrm{m}$ ) or small particles (SPs, $<500 \mu \mathrm{m}$ ), while the amounts of MPs and SPs were similar. The wet volume of LPs in Group $1(1.367 \pm 0.175 \mathrm{~mL})$ was significantly greater than that in other groups $(P<0.001$ for Groups 2 and 3, $P<0.05$ for Group 4). The wet volume of MPs in Group $3(0.232 \pm 0.069 \mathrm{~mL})$ was significantly greater than that in Groups $1(P<0.001), 2(P<0.05)$, and $4(P<0.05)$.

The dry volume of bone particles is presented in Figure 3. The dry volume of particles in all groups was less than the wet volume. The total dry and LP volume of Group 1 $(1.147 \pm 0.425 \mathrm{~mL})$ was significantly greater than in other groups (Group 2: 0.688 $\pm 0.163 \mathrm{~mL}$, Group 3: 0.699 $\pm 0.235 \mathrm{~mL}$, and Group 4: $0.74 \pm 0.311 \mathrm{~mL}, P<0.05$ for all comparisons)

The dry weight of bone particles is presented in Figure 4. In all groups, more than $0.3 \mathrm{~g}$ of bone particles were collected in this study. The total dry weight of Group $1(0.422 \pm 0.061 \mathrm{~g})$ was significantly greater than that of Group $3(P<0.05)$. The dry weight of LPs in Group $1(0.372 \pm 0.058 \mathrm{~g})$ was significantly greater than that of Groups $2(P<0.001)$ and $3(P<0.05)$.

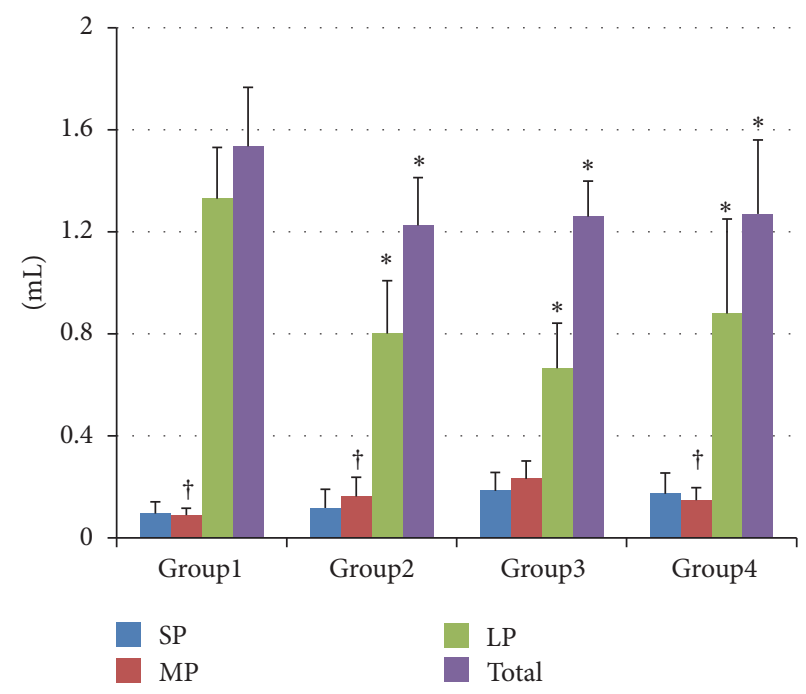

Figure 2: Wet volume $(\mathrm{mL})$ of the bone particles (mean \pm SD) collected during the 10 osteotomies. SPs: small particles, $<500 \mu \mathrm{m}$, MPs: medium particles, $500-1000 \mu \mathrm{m}$, and LPs: large particles, $>1000 \mu \mathrm{m}$. *Statistically significant compared to Group 1 in the same category of bone particles. ${ }^{\dagger}$ Statistically significant compared to Group 3 in the same category of bone particles.

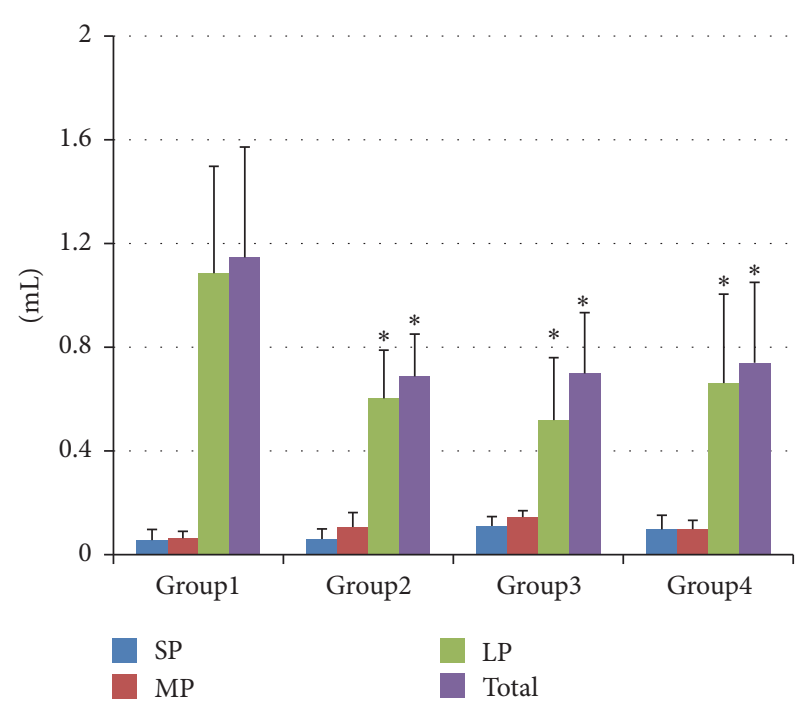

FIgure 3: Dry volume $(\mathrm{mL})$ of the bone particles (mean $\pm \mathrm{SD}$ ) collected during the 10 osteotomies. SPs: small particles, $<500 \mu \mathrm{m}$, MPs: medium particles, $500-1000 \mu \mathrm{m}$, and LPs: large particles, $>1000 \mu \mathrm{m} .{ }^{*}$ Statistically significant compared to Group 1 in the same category of bone particles.

\section{Discussion}

In the present study, three commercially available drill systems were compared with a specially designed bone harvesting device. Bone collection via drilling is more convenient for the clinician and more patient-friendly compared to the use of a bone harvesting device. Irrigation to prevent excessive heat generation has been considered a major obstacle to harvesting autogenous bone via drilling 


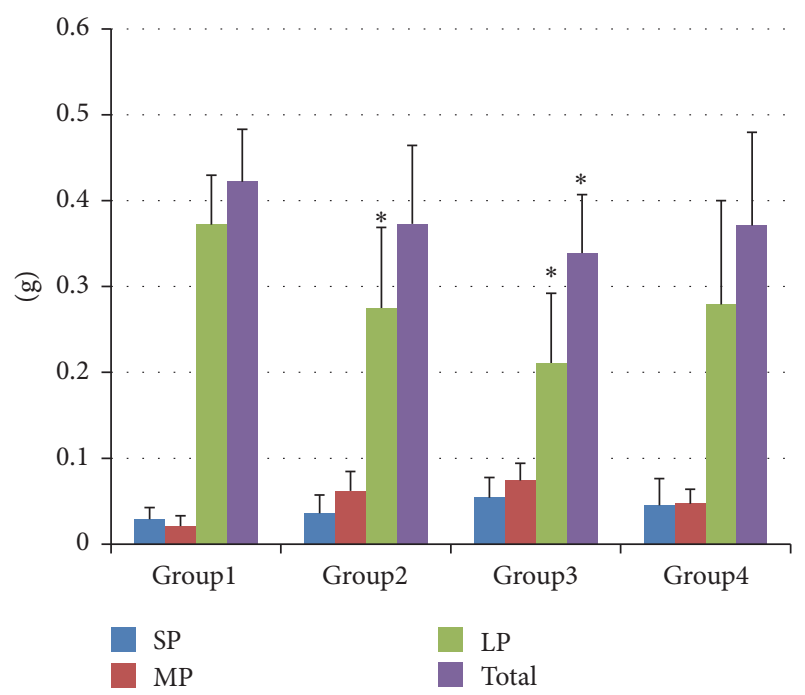

FIGURE 4: Dry weight (g) of the bone particles (mean \pm SD) collected during the 10 osteotomies. SPs: small particles, $<500 \mu \mathrm{m}$, MPs: medium particles, 500-1000 $\mu \mathrm{m}$, and LPs: large particles, $>1000 \mu \mathrm{m}$. * Statistically significant compared to Group 1 in the same category of bone particles.

because it flushes away bone particles. However, there is growing evidence that irrigation can be minimized during osteotomy preparation. Anitua et al. proposed novel lowspeed (20-80 rpm) drilling procedure without irrigation [20]. The bone particles obtained by this procedure included well-preserved trabeculae in which osteocytes, osteoblasts, and lining cells could be found. Thermal imaging analysis revealed that low-speed drilling $(50 \mathrm{rpm})$ without irrigation did not cause overheating [21]. Park et al. extracted alveolar bone-derived stromal cells from bone particles obtained via minimally irrigated dental implant drilling at low speed (50-200 rpm) and demonstrated that the cells have the potential to differentiate into osteoblasts and adipocytes [14]. To date, no studies have evaluated whether drills designed for osteotomy preparation have a similar capacity of bone harvesting to specially designed bone harvesting devices. The profile of the bone particles obtained using each drilling system, such as the amount obtained and particle size, could help confirm the clinical usefulness of these techniques.

The amount of harvested bone is dependent on the cortical thickness of the donor site. Previously, the cortical bone thickness of the human mandible was investigated. In a study using cone-beam computed tomography (CBCT), the mean thickness of buccal cortical bone was $2.5 \mathrm{~mm}$ and $3.18 \mathrm{~mm}$ at the apex of mandibular first and second molar, respectively [22]. In a cadaver study, the average buccal cortical plate thickness of the edentulous posterior mandible was $2.26-2.88 \mathrm{~mm}$ [23]. In the present study, the mean cortical bone thickness of the bovine rib bones was approximately $2.3 \mathrm{~mm}$, which is clinically similar to the human mandible. At a single osteotomy site in the present study, the mean wet volume of harvested bone was $0.123-0.154 \mathrm{~mL}$. In another ex vivo study, approximately $0.5 \mathrm{~mL}$ of bone particles was collected, but the model used was the bovine mandibular body (cortical bone thickness $>5 \mathrm{~mm}$ ) [19]. Clinically, Savant et al. collected $0.195 \mathrm{~mL}$ of bone particles [24], and Kainulainen et al. collected $0.09-0.12 \mathrm{~mL}$ bone from a single implant site preparation in a human [25]. Considering this, only small peri-implant defects may be managed with the sole use of the autogenous bone harvested from a single osteotomy site, while a medium or large defect may require additional bone substitutes. Although the amount of the collected autogenous bone was not enough for sufficient contour around the implant, the autogenous bone can provide osteopromotive effect and the insufficient volume can be compensated with other bone substitutes $[26,27]$. This type of augmentation, so called contour augmentation, has been documented well previously, applying autogenous bone chips on the denuded implant surface, covering slowly resorptive bone substitute, such as deproteinized bovine bone mineral, and covering the augmentation with collagen membrane [28].

Particle size may affect bone-forming capability and volume stability. Small particles increase surface area and subsequently increase the release of growth and differentiation factors [29], whereas they tend to be rapidly resorbed and hamper space maintenance [16]. Some studies demonstrated that particle size in the range of $250-1000 \mu \mathrm{m}$ is suitable for bone formation [30-33]. Shapoff et al. reported that bone particles ranging from 125 to $1000 \mu \mathrm{m}$ had greater osteogenic activity than particles $<125 \mu \mathrm{m}$ [30]. Urist et al. reported that decalcified freeze-dried bone allografts ranging from 250 to $420 \mu \mathrm{m}$ resulted in better bone induction than those ranging from 1000-2000 $\mu \mathrm{m}$ [31]. However, in other studies, LPs $(1000-2000 \mu \mathrm{m})$ led to significantly greater bone volume and vital new bone growth compared to SPs $(150-400 \mu \mathrm{m} / 250-1000 \mu \mathrm{m})[34,35]$. Even though LPs $(1000-2000 \mu \mathrm{m})$ resulted in significantly less bone formation in the early healing period compared to SPs $(250-1000 \mu \mathrm{m})$, this difference disappeared over time [36]. In the present study, LP fractions $(>1000 \mu \mathrm{m})$ were harvested in greater amounts than MP and SP fractions. Despite the contradictory results of previous studies, the harvested bone from both the bone harvesting device and the drills used in the present study could be used for new bone formation without affecting volume stability.

When harvesting bone particles during osteotomy preparation, drill geometry may be important. Indeed, Park et al. suggested that drill morphology significantly influenced the size of collected bone particles [18]. However, there have been few studies on drill geometry for bone harvesting, and in some cases drill geometry is proprietary information of the implant company. In the authors' opinion, the number of flutes and web size should be emphasized for the total amount obtainable. The flutes are designed for discharging bone debris. A higher number of flutes indicate a narrower individual flute width, which is disadvantageous for trapping bone chips. Moreover, more flutes lead to a higher temperature during osteotomy preparation [37], which may increase the need for irrigation. The web is the core of the drill body that joins the blades. A narrower web results in a wider flute, which is beneficial for collecting bone chips, while the web dimensions should provide adequate drill strength. 
Other characteristics, such as helix angle, may also affect bone harvesting and should be further investigated.

The findings of the present study should be carefully utilized in clinical settings. First of all, clinicians cannot precisely predict cortical bone thickness from routine panoramic radiography. On three-dimensional radiography such as CBCT, the thickness can be measured preoperatively. If thin cortical bone is observed in CBCT, harvest of autogenous bone via drilling is unrealistic, and a bone harvesting device may be a better option considering that the total volume of bone harvested by the device was significantly greater compared to drilling. However, the device should be used several times at other surgical sites to obtain a sufficient amount.

Secondly, harvesting via drilling may not be feasible in bone that is too hard or soft. Osteotomy in hard bone requires high-speed drilling under a copious cooling system, in which case minimally irrigated low-speed drilling is out of the question. Soft bone sometimes requires undersized preparation, that is, reduced use of drilling, which decreases the amount of bone harvested. Also, soft bone provides an insufficient amount for harvest due to low density.

Collectively, the wet and dry volume of total bone particles and LP fractions were significantly greater when a bone harvesting device was used compared to drilling. The amount of autogenous bone harvested via drilling may be suitable for treating small peri-implant defects when it is used solely. However, the autogenous bone can be also usefully utilized due to its osteopromotive effect when it is used concomitantly with other commercial bone substitutes [26], although the amount of the harvested autogenous bone is small.

\section{Conclusion}

In the present study, a specially designed bone harvesting device and three different dental implant system drills were compared in terms of the amount of harvested bone and particle size. The amount of total bone particles and large particles $(>1000 \mu \mathrm{m})$ harvested was significantly greater when a bone harvesting device was used compared to minimally irrigated low-speed drilling with commercially available drills, but the particle size composition was similar.

\section{Conflicts of Interest}

No potential conflicts of interest relevant to this article were reported.

\section{Authors' Contributions}

Hyun-Chang Lim and Kyung-In Ha contributed equally to this study.

\section{Acknowledgments}

This study was supported by a grant from Kyung Hee University in 2013 (KHU-20131082). The authors would like to thank Dr. Hyun-jin Yim, Dr. Dong-Min Kim, and Dr. BokHee Moon for their contributions during experiments.

\section{References}

[1] M. Cushing, "Autogenous red marrow grafts: their potential for induction of osteogenesis," Journal of Periodontology, vol. 40, no. 8, pp. 492-497, 1969.

[2] C. E. Misch and F. Dietsh, "Bone-grafting materials in implant dentistry," Implant Dentistry, vol. 2, no. 3, pp. 158-167, 1993.

[3] A. Blay, S. Tunchel, and W. R. Sendyk, "Viability of autogenous bone grafts obtained by using bone collectors: histological and microbiological study," Pesquisa Odontológica Brasileira, vol. 17, no. 3, pp. 234-240, 2003.

[4] G. Widmark and C. J. Ivanoff, "Augmentation of exposed implant threads with autogenous bone chips: prospective clinical study," Clinical Implant Dentistry and Related Research, vol. 2, no. 4, pp. 178-183, 2000.

[5] M. F. Zide, "Autogenous bone harvest and bone compacting for dental implants," Compendium of Continuing Education in Dentistry, vol. 21, no. 7, pp. 585-592, 2000.

[6] A. Dasmah, A. Thor, A. Ekestubbe, L. Sennerby, and L. Rasmusson, "Particulate vs. block bone grafts: three-dimensional changes in graft volume after reconstruction of the atrophic maxilla, a 2-year radiographic follow-up," Journal of CranioMaxillo-Facial Surgery, vol. 40, no. 8, pp. 654-659, 2012.

[7] E. D. de Avila, J. S. Filho, L. T. de Oliveira Ramalho, M. F. Real Gabrielli, and V. A. Pereira Filho, "Alveolar ridge augmentation with the perforated and nonperforated bone grafts," Journal of Periodontal \& Implant Science, vol. 44, no. 1, pp. 33-38, 2014.

[8] M. Lakshmiganthan, S. Gokulanathan, N. Shanmugasundaram, R. Daniel, and S. B. Ramesh, "Piezosurgical osteotomy for harvesting intraoral block bone graft," Journal of Pharmacy and Bioallied Sciences, vol. 4, supplement 2, pp. S165-S168, 2012.

[9] P. K. Moy, S. Lundgren, and R. E. Holmes, "Maxillary sinus augmentation: histomorphometric analysis of graft materials for maxillary sinus floor augmentation," Journal of Oral and Maxillofacial Surgery, vol. 51, no. 8, pp. 857-862, 1993.

[10] L. Tolstunov, "Maxillary tuberosity block bone graft: innovative technique and case report," Journal of Oral and Maxillofacial Surgery, vol. 67, no. 8, pp. 1723-1729, 2009.

[11] D. J. Zeiter, W. L. Ries, and J. J. Sanders, "The use of a bone block graft from the chin for alveolar ridge augmentation," International Journal of Periodontics and Restorative Dentistry, vol. 20, no. 6, pp. 619-627, 2000.

[12] D. Flanagan, "Osteotomy irrigation: Is it necessary?" Implant Dentistry, vol. 19, no. 3, pp. 241-249, 2010.

[13] F. Graziani, S. Cei, S. Ivanovski, F. La Ferla, and M. Gabriele, "A systematic review of the effectiveness of bone collectors," The International Journal of Oral \& Maxillofacial Implants, vol. 22, no. 5, pp. 729-735, 2007.

[14] J.-C. Park, J. C. Kim, Y.-T. Kim et al., "Acquisition of human alveolar bone-derived stromal cells using minimally irrigated implant osteotomy: in vitro and in vivo evaluations," Journal of Clinical Periodontology, vol. 39, no. 5, pp. 495-505, 2012.

[15] Y. Reingewirtz, S. Szmukler-Moncler, and B. Senger, "Influence of different parameters on bone heating and drilling time in implantology," Clinical Oral Implants Research, vol. 8, no. 3, pp. 189-197, 1997.

[16] K. Kon, M. Shiota, M. Ozeki, Y. Yamashita, and S. Kasugai, "Bone augmentation ability of autogenous bone graft particles with different sizes: A histological and micro-computed tomography study," Clinical Oral Implants Research, vol. 20, no. 11, pp. 1240-1246, 2009. 
[17] S.-M. Jeong, J.-H. Yoo, Y. Fang, B.-H. Choi, J.-S. Son, and J.H. Oh, "The effect of guided flapless implant procedure on heat generation from implant drilling," Journal of Cranio-MaxilloFacial Surgery, vol. 42, no. 6, pp. 725-729, 2014.

[18] S.-Y. Park, S.-Y. Shin, S.-M. Yang, and S.-B. Kye, "Effect of implant drill design on the particle size of the bone collected during osteotomy," International Journal of Oral and Maxillofacial Surgery, vol. 39, no. 10, pp. 1007-1011, 2010.

[19] H. G. Kim et al., "Volumetric comparison of three different innovative bone collecting devices for autogenous bone grafts," Quintessence International, vol. 46, no. 9, pp. 807-815, 2002.

[20] E. Anitua, C. Carda, and I. Andia, "A novel drilling procedure and subsequent bone autograft preparation: a technical note," The International Journal of Oral \& Maxillofacial Implants, vol. 22, no. 1, pp. 138-145, 2007.

[21] S.-J. Kim, J. Yoo, Y.-S. Kim, and S.-W. Shin, “Temperature change in pig rib bone during implant site preparation by lowspeed drilling," Journal of Applied Oral Science, vol. 18, no. 5, pp. 522-527, 2010.

[22] B. A. Al-Jandan, A. A. Al-Sulaiman, H. F. Marei, F. A. Syed, and M. Almana, "Thickness of buccal bone in the mandible and its clinical significance in mono-cortical screws placement. A CBCT analysis," International Journal of Oral and Maxillofacial Surgery, vol. 42, no. 1, pp. 77-81, 2013.

[23] D. J.-M. Leong, J. Li, I. Moreno, and H.-L. Wang, "Distance between external cortical bone and mandibular canal for harvesting ramus graft: A human cadaver study," Journal of Periodontology, vol. 81, no. 2, pp. 239-243, 2010.

[24] T. D. Savant, K. S. Smith, S. M. Sullivan et al., "Bone volume collected from dental implant sites during osteotomy," Journal of Oral and Maxillofacial Surgery, vol. 59, no. 8, pp. 905-907, 2001.

[25] V. T. Kainulainen, T. J. Kainulainen, K. S. Oikarinen, R. P. Carmichael, and G. K. B. Sàndor, "Performance of six bone collectors designed for dental implant surgery," Clinical Oral Implants Research, vol. 17, no. 3, pp. 282-287, 2006.

[26] S. F. M. Janner, D. D. Bosshardt, D. L. Cochran et al., "The influence of collagen membrane and autogenous bone chips on bone augmentation in the anterior maxilla: a preclinical study," Clinical Oral Implants Research, vol. 28, no. 11, pp. 1368-1380, 2017.

[27] I.-K. Lee, H.-C. Lim, J.-S. Lee, J.-Y. Hong, S.-H. Choi, and U.W. Jung, "Layered approach with autogenous bone and bone substitute for ridge augmentation on implant dehiscence defects in dogs," Clinical Oral Implants Research, vol. 27, no. 5, pp. 622628, 2016.

[28] V. Chappuis, L. Rahman, R. Buser, S. Janner, U. Belser, and D. Buser, "Effectiveness of contour augmentation with guided bone regeneration: 10-year results," Journal of Dental Research, 2017.

[29] L. Pallesen, S. Schou, M. Aaboe, E. Hjørting-Hansen, A. Nattestad, and F. Melsen, "Influence of particle size of autogenous bone grafts on the early stages of bone regeneration: a histologic and stereologic study in rabbit calvarium," The International Journal of Oral \& Maxillofacial Implants, vol. 17, no. 4, pp. 498506, 2002.

[30] C. A. Shapoff, G. M. Bowers, B. Levy, J. T. Mellonig, and R. A. Yukna, "The effect of particle size on the osteogenic activity of composite graft of allogeneic freeze-dried bone and autogenous marrow," Journal of Periodontology, vol. 51, no. 11, pp. 625-630, 1980.
[31] M. R. Urist, B. F. Silverman, K. Buring, F. L. Dubuc, and J. M. Rosenberg, "The bone induction principle," Clinical Orthopaedics and Related Research, vol. 53, pp. 243-283, 1967.

[32] H. Xu, Y. Shimizu, S. Asai, and K. Ooya, "Experimental sinus grafting with the use of deproteinized bone particles of different sizes," Clinical Oral Implants Research, vol. 14, no. 5, pp. 548-555, 2003.

[33] D. J. Zaner and R. A. Yukna, "Particle size of periodontal bone grafting materials," Journal of Periodontology, vol. 55, no. 7, pp. 406-409, 1984.

[34] K. Kon, M. Shiota, M. Ozeki, and S. Kasugai, "The Effect of graft bone particle size on bone augmentation in a rabbit cranial vertical augmentation model: A microcomputed tomography study," The International Journal of Oral \& Maxillofacial Implants, vol. 29, no. 2, pp. 402-406, 2014.

[35] T. Testori, S. S. Wallace, P. Trisi, M. Capelli, F. Zuffetti, and M. Del Fabbro, "Effect of xenograft (ABBM) particle size on vital bone formation following maxillary sinus augmentation: A multicenter, randomized, controlled, clinical histomorphometric trial," International Journal of Periodontics and Restorative Dentistry, vol. 33, no. 4, pp. 467-475, 2013.

[36] S. S. Jensen, M. Aaboe, S. F. M. Janner et al., "Influence of particle size of deproteinized bovine bone mineral on new bone formation and implant stability after simultaneous sinus floor elevation: A histomorphometric study in minipigs," Clinical Implant Dentistry and Related Research, vol. 17, no. 2, pp. 274285, 2015.

[37] H. Oh, B. Kim, H. Kim, I. Yeo, U. Wikesjö, and K. Koo, "Implant drill characteristics: thermal and mechanical effects of two-, three-, and four-fluted drills," The International Journal of Oral \& Maxillofacial Implants, vol. 32, no. 3, pp. 483-488, 2017. 


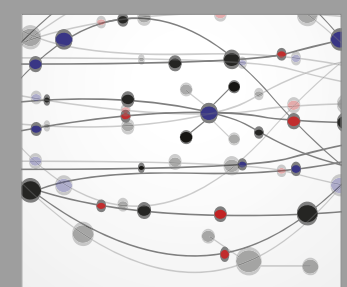

The Scientific World Journal
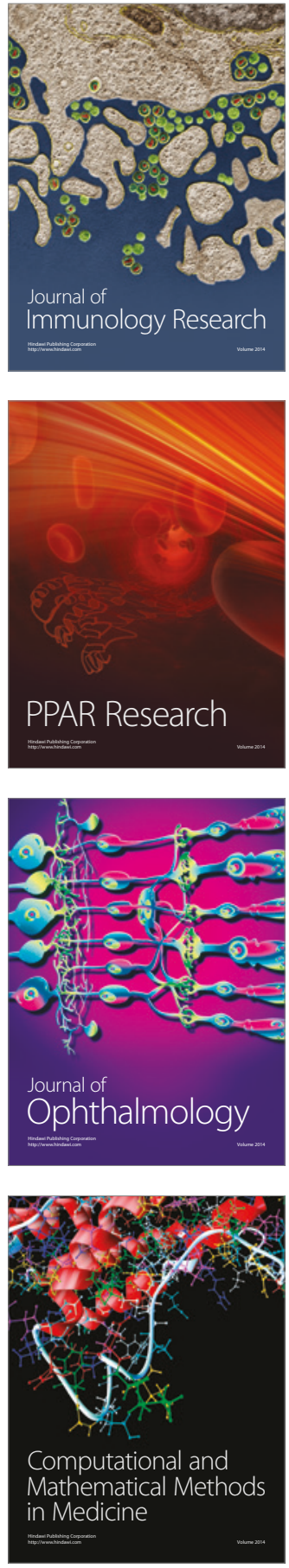

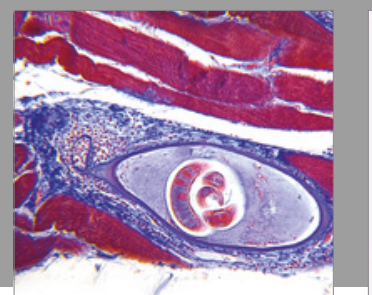

Gastroenterology Research and Practice
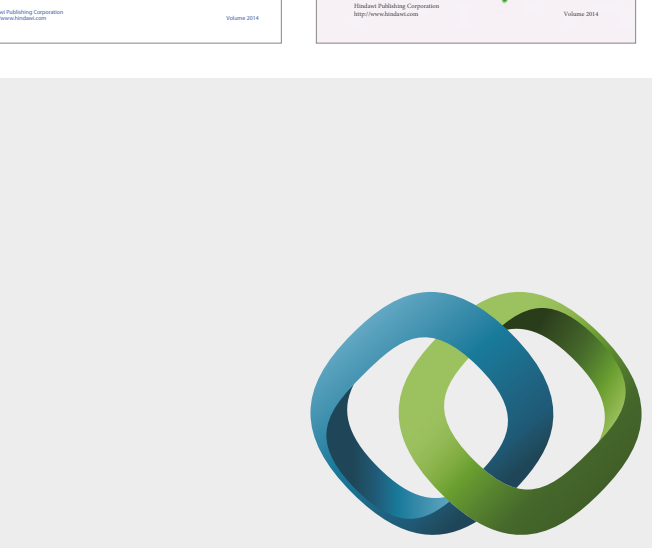

\section{Hindawi}

Submit your manuscripts at

https://www.hindawi.com
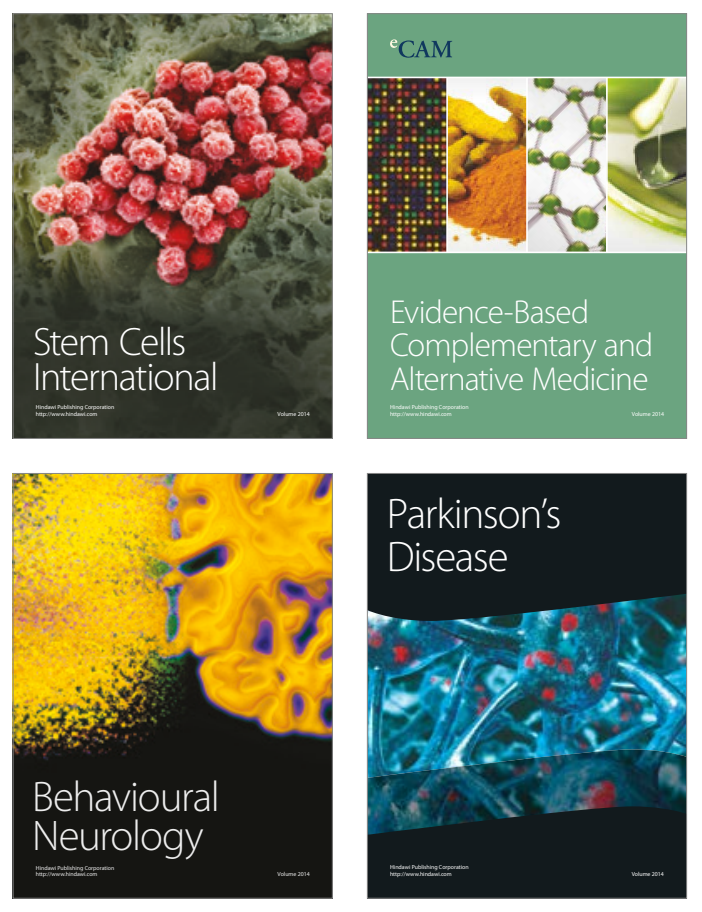
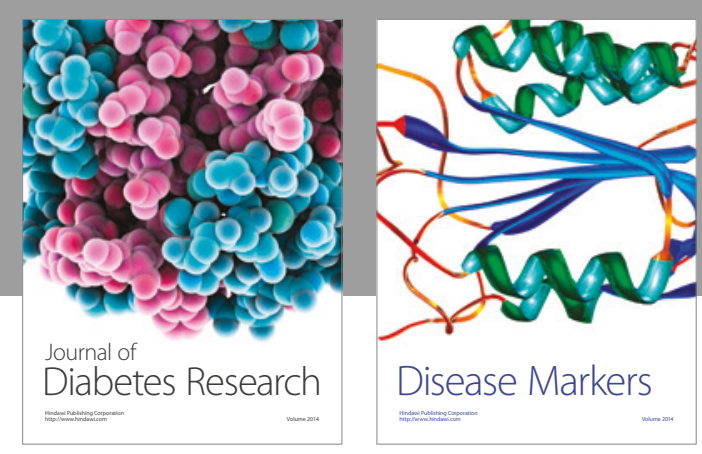

Disease Markers
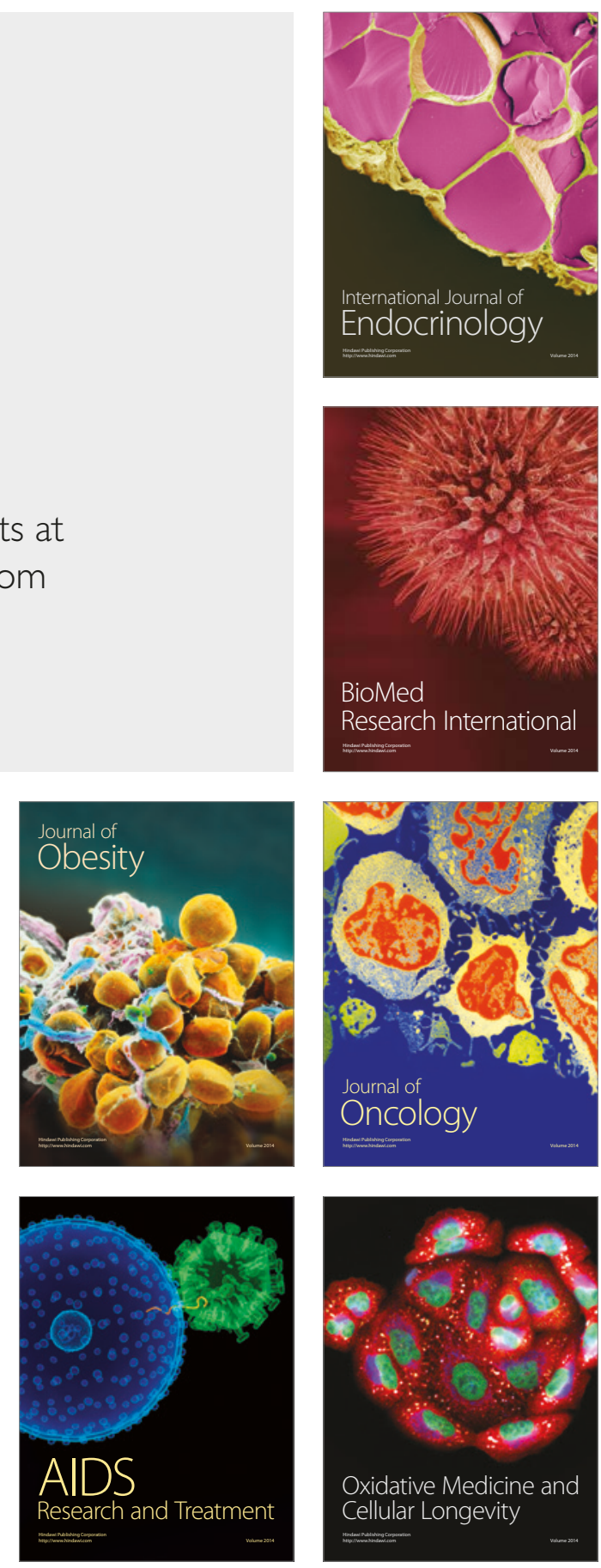